\title{
Exploratory analysis of seasonal mortality in England and Wales, 1998 to 2007
}

Gary Brown, Vanessa Fearn and Claudia Wells Office for National Statistics

\begin{abstract}
Background

This article reports research carried out to inform possible methods of describing seasonal mortality in relation to extremes of temperature. In particular, since different methods are currently used to assess excess winter mortality and heatwave related mortality, we aimed to find out whether a single method could be used to measure all seasonal mortality in relation to temperature. In order to do this the project investigated whether there are temperatures above or below which excess deaths occur, and explored whether it is possible to predict reliably how many deaths would occur at extreme temperatures.
\end{abstract}

Method

Daily and monthly Central England Temperatures for 1998 to 2007 were supplied by the Met Office Hadley Centre and daily death occurrence data between 1993 and 2007 was extracted from the death registrations database held by the Office for National Statistics (ONS). Least squares regression, based on the previous five years of data, was used to predict expected mortality, and excess mortality was calculated as the difference between the expected mortality and the observed mortality on any given day.

Statistically significant increases in both daily deaths and temperatures were investigated with the probability of excess mortality assessed on those days. Two regression models were calculated, one for deaths and temperature and one for excess deaths and temperature.

\section{Results}

Five days with statistically significant excess mortality were identified over the period 1 January 1998 to 31 December 2007, the largest being on 31 December 1999. Three of the five days identified coincided with extremely hot weather occurring in August 2003 and July 2006. However, more extreme temperatures were seen on some days with no excess mortality, so predicting mortality using extreme temperatures alone would cause frequent false positive results. 
Regression models based on daily death and temperature explained only 8 per cent of the variance in summer mortality and 7 per cent of the variance in winter mortality. The models based on excess deaths and temperature explained 20 per cent of the variance in excess mortality in summer, but only 1 per cent of the variance in excess mortality in winter.

\section{Conclusion}

There is a weak but significant relationship between temperature and mortality in both the summer and winter months. While in winter mortality does increase as it gets colder, winter mortality is variable and high mortality can occur on relatively mild days. Similarly, in the summer high temperatures are often associated with relatively increased mortality, but a single hot day does not always lead to excess deaths. Daily mortality cannot be predicted from temperature alone: the prevalence of influenza in winter and factors such as air pollution in summer should also be considered. 


\section{Contents}



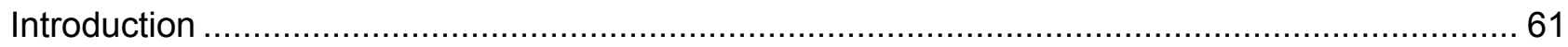



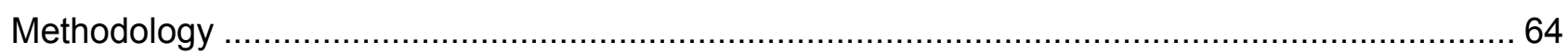

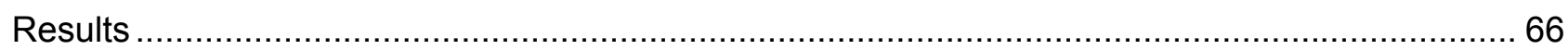



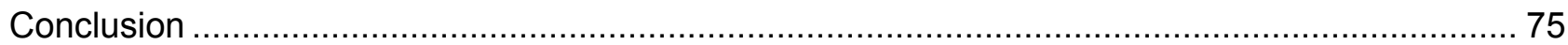

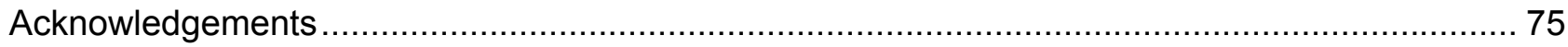



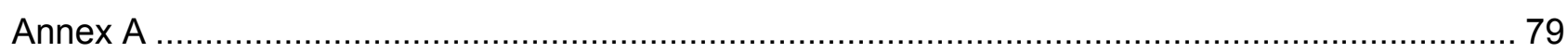

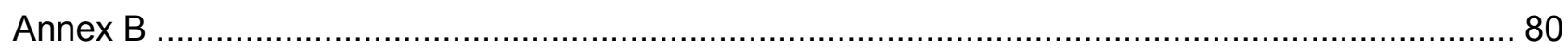

\section{List of Figures}

Figure 1 Mean number of daily deaths and average temperature per month in England and Wales, 1993-2007.

Figure 2 Daily mortality in England and Wales against the mean daily Central England Temperature, 1993-2007

\section{List of Tables}

Table 1 Daily deaths per month in England and Wales, 1993-2007

Table 2 All days identified as having statistically significant excess mortality between January 1998 and December 2007

Table 3 Probability of temperatures associated with excess mortality events, average and minimum temperature probabilities for those months

Table $4 \quad$ Summer heatwaves identified where daily maximum CETs exceeded 10 year

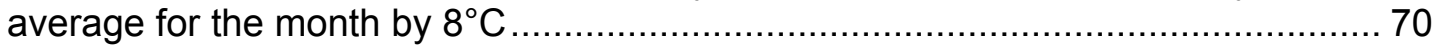

Table A1 Example calculation of normalised daily deaths on 01 January 2000 ..................79 


\section{Introduction}

In England and Wales more deaths occur in winter than in summer, with summer mortality typically being low and stable. Excess winter mortality (EWM) is calculated by comparing the number of deaths occurring in winter with the number occurring in a non-winter period. A previous analysis compared methods of calculating EWM using different winter and non-winter periods (Johnson and Griffiths, 2003). However, The Office for National Statistics (ONS) currently uses the same method as the World Health Organisation Regional Office for Europe (WHO, 2010) to produce its annual EWM figure and index (see Box 1). This is a simple way to assess mortality levels over the winter as a whole and allows comparisons to be made with previous years. The EWM index can be used to compare numbers of excess deaths between sexes, age groups, regions and countries.

\section{Box 1 Standard ONS method for calculating excess winter mortality (EWM)}

The standard method defines the winter period as December to March, and compares the number of deaths that occurred in this winter period with the average number of non-winter deaths occurring in the preceding August to November and the following April to July:

$E W M=$ Dec to Mar deaths $-(($ Aug to Nov deaths + Apr to Jul deaths $) / 2)$

The EWM index is calculated as the number of excess winter deaths divided by the average non-winter deaths expressed as a percentage:

EWM Index $=(E W M /$ average non-winter deaths $) \times 100$

The EWM index is normally presented with 95 per cent confidence intervals, which are calculated as:

EWM index $\pm 1.96 \times(E W M$ Index / $\sqrt{ }$ EWM $)$

Johnson and Griffiths (2003) reported that in England and Wales between 1950 and 1999 the months from December to March had above average daily mortality; November and April had average mortality; and May to October had below average mortality - compared to the average daily mortality for the entire period. This supports the ONS method of calculating EWM based on a winter period defined as December to March. The definition of a non-winter period is somewhat less clear. Johnson and Griffiths showed that if mortality is unusually high in November or April (or in any of the non-winter months), estimates of EWM are actually reduced, as the autumn and spring months are included in the non-winter comparison period. This is a limitation of the current method of measuring EWM. A second drawback is that the current method does not account for the long-term declining trend in mortality in England and Wales. The final disadvantage of the current method is its timeliness. In order to produce EWM figures, the numbers of deaths occurring in the subsequent four months (April to July of the current year) are needed. This means that EWM 
figures cannot be published until the following autumn. A method which could produce estimates of EWM more quickly would be welcomed by users.

Although mortality during the summer months is generally low, during heatwaves mortality increases, though not to the level of winter mortality (Johnson et al., 2005). The standard ONS method for calculating excess summer mortality is the number of observed deaths during a specific heatwave period minus the baseline expected mortality (average of the number of deaths during the same period over the previous five years).

This article reports research carried out to inform possible alternative methods of describing seasonal mortality in relation to extremes of temperature. In particular, since different methods are currently used to assess excess winter mortality and heatwave related mortality, we aimed to find out whether a single method can be used to measure all seasonal mortality in relation to temperature. The findings are intended to help inform policy responses to extreme temperature events and facilitate further research into the causes of seasonal mortality. In order to do this the project investigated whether there are temperatures above or below which excess deaths occur and explored whether it is possible to predict reliably how many deaths would occur at extreme temperatures.

\section{Background}

\section{Heatwave mortality}

England and Wales, like other countries in Europe, experienced a severe heatwave in August 2003. This heatwave led to more than 2,000 excess deaths, a 16 per cent increase in deaths compared to the baseline for that calendar period (Johnson et al., 2005 and Office for National Statistics, 2005). In Johnson et al.'s study, the heatwave period was defined according to when the maximum Central England Temperature (CET) exceeded average values from 1971 to 2000 by $8^{\circ} \mathrm{C}$. Although CETs were used to define the heatwave, the impact was greatest in the southern half of England, particularly in London. On 10 August 2003 a record-breaking temperature of $38.5^{\circ} \mathrm{C}$ was reached in Faversham (Kent), and in London deaths during this heatwave period were 42 per cent higher than the five-year average. The elderly are particularly vulnerable to heatwave related mortality, and in London there was a 59 per cent increase in deaths in those over the age of 75 (Johnson et al., 2005).

The large number of excess deaths during the August 2003 heatwave prompted the Department of Health to develop a 'Heatwave Plan for England' (DH, 2010). The Met Office defined a set of heatwave thresholds for day and night time temperatures. These vary from region to region, but the average threshold temperature is $30^{\circ} \mathrm{C}$ during the day and $15^{\circ} \mathrm{C}$ overnight.

During July 2006 another heatwave occurred, but the impact of this heatwave on mortality was not as great as in August 2003. Between 16 and 28 July 2006 there were 680 excess deaths, with mortality peaking on 19 July. This was a 4 per cent increase in deaths, compared with the five-year average, much less than the 16 per cent increase seen in the August 2003 heatwave (Office for National Statistics, 2006). 
Conditions directly caused by heat (for example heatstroke) are rarely certified as the underlying cause of death. Instead, heatwave related mortality is more pronounced for respiratory and cerebrovascular diseases (Rooney et al., 1998). In their review of the relationship between heat and mortality, Basu and Samet (2002) suggest that this is because people with pre-existing respiratory, and/or cerebrovascular diseases are more susceptible to death during heatwaves. This may be because thermoregulation can be impaired in the elderly and the chronically ill, making them more vulnerable to overheating (Department of Health, 2010).

\section{Winter mortality}

Excess winter mortality varies widely within Europe; in England and Wales there were 36,450 excess deaths in the winter of 2008/09, which amounts to 24 per cent more deaths in winter compared to the non-winter period (ONS, 2010). A study by Healy (2003) showed that in 14 European countries between 1988 and 1997 the winter increase ranged from 10 to 28 per cent. During this time period England and Wales both had slightly higher than average EWM (19 and 17 per cent respectively). This study showed that Finland, a country with very cold winters, had the lowest EWM, and Portugal, a country with milder winters, had the highest EWM. Consistent with this, the Eurowinter group found that percentage increases in mortality per $1^{\circ} \mathrm{C}$ fall in temperature below $18^{\circ} \mathrm{C}$ were greater in warmer European regions (for example Athens) than in colder regions (for example North Finland). This demonstrates the need to consider extremes of temperature in relation to country-specific temperature distributions, because absolute temperature alone cannot explain EWM.

Research suggests that EWM is higher in countries that take fewer precautions against the cold, both indoors and outdoors. For instance, a relationship has been found between EWM and measures of the thermal efficiency of homes, such as the percentage of houses that have cavity wall insulation (Healy, 2003). It has also been found that areas with older properties and areas where homes had a low indoor temperature have higher EWM from cardiovascular disease (Wilkinson et al., 2001). The Eurowinter group (1997) reported that compared to people living in countries with cold winters, those from warmer countries were less likely to wear warm protective clothing, like hats, in cold weather. They were also more likely to remain inactive whilst outdoors. One study found that cold-related mortality in working age men was lower for unskilled occupations than for any other social class. The authors suggested this was because the internal heat produced from manual work protected these men from cold-stress (Donaldson and Keatinge, 2003).

As with heatwave mortality, conditions directly relating to cold, such as hypothermia, are not the main cause of excess winter deaths. The majority of additional winter deaths are caused by cerebrovascular diseases, ischaemic heart disease and respiratory disorders (The Eurowinter group, 1997). In contrast, there is very little seasonal variation in conditions such as cancer (Johnson and Griffiths, 2003). The cold can have various physiological effects, which may lead to death in vulnerable people. The Eurowinter group (1997) noted that cold causes

haemoconcentration, which leads to thrombosis; and that cold can also lower the immune system's resistance to respiratory infections. Additionally, the level of influenza circulating in the population increases in winter; and in vulnerable groups, such as the elderly or those with pre-existing health problems, influenza can lead to life-threatening complications, such as bronchitis or secondary bacterial pneumonia (HPA, 2010). 
In common with heatwave mortality, much higher excess winter mortality is seen in the elderly population than in younger people. Consequently, measures that aim to reduce EWM, such as winter fuel payments (DirectGov, 2010) and flu vaccinations (NHS, 2010) are targeted at older people.

\section{Methodology}

The analysis presented here uses two main sources of data: temperature data supplied by the Met Office Hadley Centre and ONS mortality data.

\section{Temperature data}

The Met Office Central England Temperature (CET) dataset was used to identify extreme temperatures from 1998 to 2007 . The dataset contains daily and monthly temperatures, which are representative of a roughly triangular area of the UK enclosed by Lancashire, London and Bristol. The weather stations used to compile CET are chosen from the UK surface station network to be as consistent as possible with those used historically. The data are then adjusted to ensure consistency with the historical series (Parker et al., 1992).

\section{Mortality data}

Data on deaths occurring in England and Wales on each day from 1993 to 2007 were extracted from the death registrations database held by ONS.

\section{Statistical techniques used \\ Measuring actual and expected mortality}

Firstly, an exploratory analysis of mortality patterns in England and Wales was carried out. Descriptive statistics for monthly deaths and graphical analyses of the relationship between mortality and temperatures were produced.

Following preliminary analyses (not reported here) least squares regression was found to be the best method for estimating expected deaths based on the same period in the previous five years. Therefore, in the following sections least squares regression was used to predict expected mortality. Excess mortality was calculated as the difference between the expected mortality and the observed number of deaths on any given day.

\section{Identifying statistically significant increases in daily deaths}

Daily deaths from 1993 to 2007 were used, which enabled 10 years of excess mortality values for each month to be estimated (January 1998 to December 2007). Average daily deaths were calculated for each month in each year from January 1993 to December 2006 (that is the average number of deaths on each day in January 1993, February 1993 ... to December 2006). The expected average daily deaths for a month were predicted with least squares regression using the previous five years' averages. This formed a distribution of 10 years excess daily deaths for each month - around 300 values. The mean and standard deviation of the excess daily deaths were then calculated for each month from these distributions. The excess mortality data were then 
normalised by subtracting the mean and dividing by the standard deviation. The normalised data were tested against the normal $[\mathrm{N}(0,1)]$ distribution to identify days with statistically significant excess mortality. The test statistic was adjusted using the Bonferroni method to correct for multiple significance tests (see Field, 2009 for an explanation of the Bonferroni method). An example calculation can be found in Annex A.

Once days with statistically significant excess mortality were identified, the temperatures on these dates were examined.

\section{Identifying extreme temperatures}

Central England Temperature (CET) data from 1993 to 2007 were used to identify extreme temperatures (ET) from 1998 to 2007. As with deaths, normalised temperatures were tested against the normal distribution to identify which were statistically significant. Daily mean temperatures were compared to the distribution of temperatures in the month over the last 10 years.

\section{Probability of excess mortality}

The probability of seeing a temperature as extreme as that which actually occurred on each day was calculated. An example calculation can be found in Annex B. In each month, the temperature probabilities were compared for days with significant excess mortality and the average for all other days.

\section{Comparison with heatwave thresholds}

In a previous analysis of summer mortality, heatwave periods were defined as when the maximum daily CET exceeded average values between 1971 and 2000 by $8^{\circ} \mathrm{C}$ (Johnson et al., 2005). Given that temperatures have risen during this period, daily temperatures that are in line with this increasing trend may be high compared to a 30-year average, meaning that too many heatwaves will be identified. Therefore a slightly different definition was used here: daily maximum CETs were compared to the 10-year average for the month. The number of excess deaths and the probability of seeing mortality as extreme as this on each identified heatwave day were then examined to determine how useful this definition of a heatwave was.

\section{Regression}

\section{Deaths and temperature}

Firstly, regression analyses were carried out, regressing daily deaths against daily temperatures. Since the relationship between mortality and temperature is not linear, two sets of regression analyses were performed: one for the summer period (June to August) and one for the winter period (December to February). Previous research suggests there is a lag effect in winter (The Eurowinter group, 1997), meaning that cold temperatures do not cause an immediate increase in deaths, instead mortality peaks several days later. Therefore the temperature was lagged to allow the impact on deaths the following day, two days on, up to seven days on. In effect the deaths were regressed against the temperature on the previous day, and two days before, up to seven days before. 


\section{Excess mortality and temperature}

In a second analysis, daily excess mortality was regressed against temperature to explore the relationship. Excess mortality was calculated using the least squares regression method described in section 1. Since five years of data were needed to calculate excess mortality on a given day, only data from 1998 to 2007 were used in this part of the analysis. This regression analysis was repeated separately for summer and winter periods. The significance of several different lag periods was tested in the winter analysis.

\section{Results}

\section{Mortality patterns in England and Wales}

Table 1 and figure 1 show that on average there are 1,478 deaths per day in England and Wales. However, the number of daily deaths varies considerably throughout the year, from just 1,100 in July 2006 to 2,798 in January 2000. Daily deaths are lowest between May and October, and are fairly stable. Daily deaths in December and January are significantly higher than during the rest of the year, and the numbers of deaths in these months is also much more variable. On average there were 1,337 deaths in summer and 1,699 in winter. Figure 1 shows that temperatures are highest in July and August and lowest in December, January and February.

\section{Table $1 \quad$ Daily deaths per month in England and Wales, 1993-2007}

\begin{tabular}{lrrrrr}
\hline Month & Mean & SD & Min & Max & Range \\
\hline January & 1,795 & 262 & 1,377 & 2,798 & 1,421 \\
February & 1,605 & 82 & 1,351 & 1,845 & 494 \\
March & 1,536 & 90 & 1,293 & 1,811 & 518 \\
April & 1,468 & 80 & 1,254 & 1,712 & 458 \\
May & 1,392 & 71 & 1,212 & 1,617 & 405 \\
June & 1,361 & 73 & 1,125 & 1,668 & 543 \\
July & 1,335 & 74 & 1,100 & 1,567 & 467 \\
August & 1,314 & 78 & 1,156 & 1,696 & 540 \\
September & 1,337 & 81 & 1,122 & 1,563 & 441 \\
October & 1,414 & 96 & 1,173 & 1,709 & 536 \\
November & 1,494 & 132 & 1,239 & 2,018 & 779 \\
December & 1,687 & 241 & 1,307 & 2,739 & 1,432 \\
Annual & 1,478 & 197 & 1,100 & 2,798 & 1,698 \\
\hline
\end{tabular}


Figure 1 Mean number of daily deaths and average temperature per month in England and Wales, 1993-2007

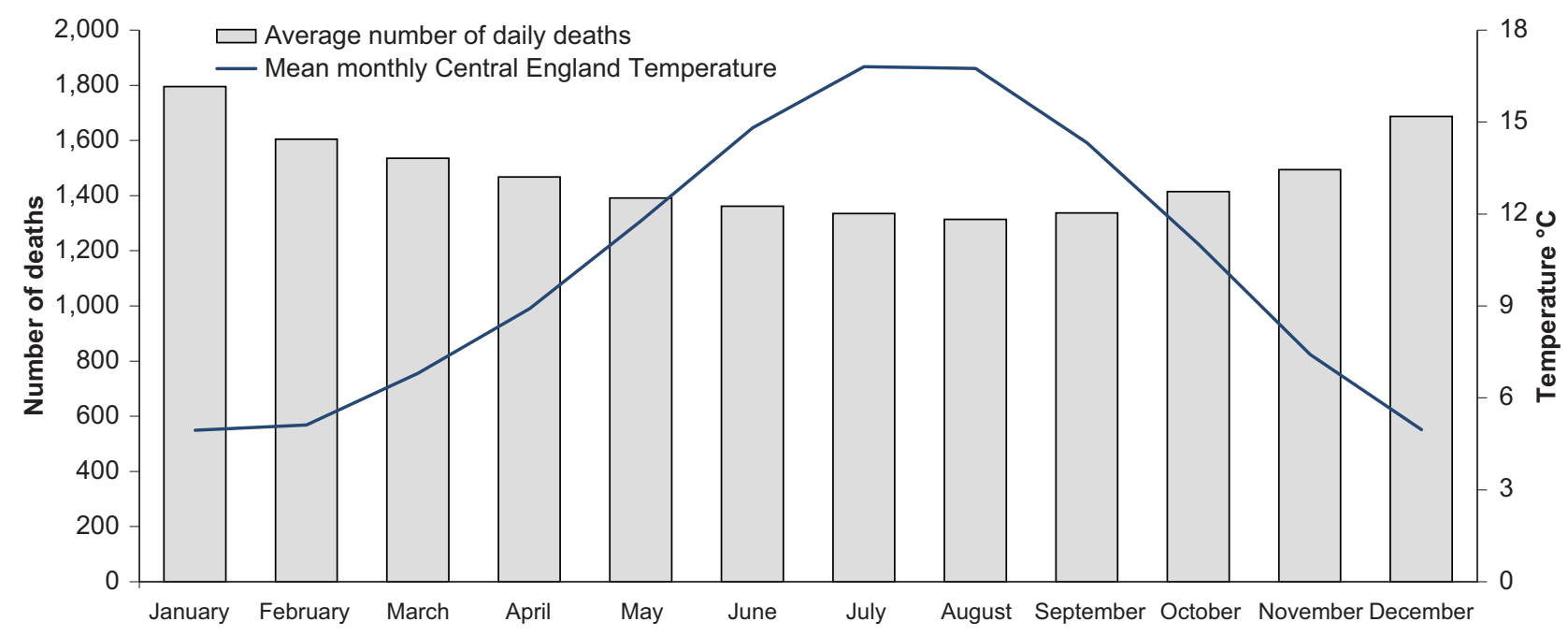

Figure 2 Daily mortality in England and Wales against the mean daily Central England Temperature, 1993-2007




Figure 2 shows that the relationship between temperature and mortality is not linear. The curve can be described as $\mathrm{J}$ shaped, as deaths are lowest when temperatures are average (around $15^{\circ} \mathrm{C}$ ), highest at colder temperatures, but also increase at extremely hot temperatures. Moreover, the scatterplot clearly shows there is much greater variability in mortality when mean temperatures fall below about $11^{\circ} \mathrm{C}$.

\section{Identifying excess mortality}

Five days with statistically significant excess mortality were identified (see Table 2). The largest excess mortality occurred on 31 December 1999, when there were more than 900 extra deaths. In addition, the method identified excess mortality for three separate periods coinciding with extremely hot weather. More than 400 excess deaths occurred on both the 10 and 11 August 2003; and 270 excess on 19 July 2006. This corresponds to known heatwaves experienced in the UK during these two periods. Finally, more than 300 excess deaths occurred on 19 June 2000. Further investigation revealed that 18 June was the hottest day of the year, with CETs reaching $29.4^{\circ} \mathrm{C}$.

\section{Table $2 \quad$ All days identified as having statistically significant excess mortality between January 1998 and December 2007}

\begin{tabular}{|c|c|c|c|c|c|c|c|}
\hline Year & Month & Day & $\begin{array}{l}\text { Actual } \\
\text { deaths }\end{array}$ & $\begin{array}{r}\text { Predicted } \\
\text { Deaths }\end{array}$ & $\begin{array}{r}\text { Excess } \\
\text { Mortality }\end{array}$ & Min CET & Max CET \\
\hline 1999 & December & 31 & 2,739 & 1,808 & 931 & 3.4 & 8.7 \\
\hline 2000 & June & 19 & 1,668 & 1,343 & 325 & 15.2 & 27.8 \\
\hline 2003 & August & 10 & 1,680 & 1,273 & 407 & 16.4 & 28.5 \\
\hline 2003 & August & 11 & 1,696 & 1,273 & 423 & 16.2 & 26.5 \\
\hline 2006 & July & 19 & 1,513 & 1,243 & 270 & 16.0 & 32.9 \\
\hline
\end{tabular}

\section{Identifying extremes of temperature}

We found that temperatures were less volatile than deaths. Only one extreme temperature event (relative to the monthly average) was identified: on 18 October 1998 the mean CET temperature was $0.1^{\circ} \mathrm{C}$, but the average temperature in October was $11.1^{\circ} \mathrm{C}$. However, this unseasonably cold weather was not related to an excess mortality event.

\section{Probability of excess mortality}

We compared the probabilities of extreme temperatures occurring for the five days identified as having significant excess mortality, with the average temperature probabilities all other days. Relatively extreme temperatures occurred on all summer days with excess mortality, but on millennium eve temperatures were not unusually cold. However, the minimum probabilities on days with no excess mortality are always much lower than the average probability on excess mortality days. That is, more extreme temperatures were seen on days with no excess mortality, hence false positives would proliferate if using temperature to predict significant excess mortality. 


\section{Table 3 Probability of temperatures associated with excess mortality events, average and minimum temperature probabilities for those months}

\begin{tabular}{|c|c|c|c|c|}
\hline Month & Period & $\begin{array}{r}\text { Excess } \\
\text { mortality } \\
\text { event? }\end{array}$ & $\begin{array}{r}\text { Average probability } \\
\text { of daily } \\
\text { temperature(s) }\end{array}$ & $\begin{array}{r}\text { Minimum } \\
\begin{array}{r}\text { probability of daily } \\
\text { temperature }\end{array}\end{array}$ \\
\hline \multirow[t]{2}{*}{ June } & 19 June 2000 & Yes & 0.01 & \\
\hline & All other days in June 1998-2007 & No & 0.53 & 0.002 \\
\hline \multirow[t]{2}{*}{ July } & 19 July 2006 & Yes & 0.01 & \\
\hline & All other July days in 1998-2007 & No & 0.50 & 0.003 \\
\hline \multirow[t]{2}{*}{ August } & 10-11 August 2003 & Yes & 0.03 & \\
\hline & All other August days in 1998-2007 & No & 0.56 & 0.001 \\
\hline \multirow[t]{2}{*}{ December } & 31 December 1999 & Yes & 0.72 & \\
\hline & All other December days in 1998-2007 & No & 0.47 & 0.004 \\
\hline
\end{tabular}

\section{Comparison with heatwave thresholds}

Twenty five heatwave days (in 14 separate periods) were identified where daily maximum CETs exceeded the 10 -year average for the month by $8^{\circ} \mathrm{C}$. However, a number of the heatwaves identified occurred in spring or autumn, and although the temperatures were hot for that time of year, they were not hot in absolute terms. So, with the exception of 27 May 2005, they did not cause excess mortality. Therefore only summer heatwaves are presented in Table 4. Of the summer heatwaves identified, just over half were associated with higher levels of mortality, shown by the fact that the probability of mortality being as high as was seen on those days was below 0.05 .

This method identified two of the excess mortality days shown in Table 3: 19 June 2000 and 19 July 2006. The hottest day of the August 2003 heatwave (09 August) was also identified, but the two days with statistically significant excess mortality (10 and 11 August) were not identified as heatwave days, as they were slightly cooler (although minimum night time temperatures were actually hotter on 10 and 11 August). 


\section{Table $4 \quad$ Summer heatwaves identified where daily maximum CETs exceeded 10 -year average for the month by $8^{\circ} \mathrm{C}$}

\begin{tabular}{|c|c|c|c|c|}
\hline Date & $\begin{array}{l}\text { Maximum daily } \\
\text { temperature } l^{\circ} \mathrm{C}\end{array}$ & $\begin{array}{r}\text { Average maximum } \\
\text { temperature for that } \\
\text { day } /{ }^{\circ} \mathrm{C}\end{array}$ & Excess mortality & $\begin{array}{r}\text { Probability of excess } \\
\text { mortality }\end{array}$ \\
\hline 31 Jul 1999 & 29.7 & 21.2 & 0 & 0.99 \\
\hline 18 Jun 2000 & 29.4 & 19.4 & 126 & 0.04 \\
\hline 19 Jun $2000^{1}$ & 27.8 & 19.4 & 325 & $<0.01$ \\
\hline 26 Jun 2001 & 28.8 & 19.4 & 125 & 0.04 \\
\hline 14 Jul 2003 & 29.6 & 21.2 & 32 & 0.68 \\
\hline 15 Jul 2003 & 31.1 & 21.2 & 187 & 0.01 \\
\hline 05 Aug 2003 & 29.1 & 21.1 & 205 & 0.01 \\
\hline 09 Aug 2003 & 32.8 & 21.1 & 299 & $<0.01$ \\
\hline 18 Jun 2005 & 27.6 & 19.4 & 54 & 0.38 \\
\hline 19 Jun 2005 & 29.1 & 19.4 & 201 & $<0.01$ \\
\hline 17 Jul 2006 & 29.6 & 21.2 & 116 & 0.09 \\
\hline $18 \mathrm{Jul} 2006$ & 30.9 & 21.2 & 195 & $<0.01$ \\
\hline 19 Jul $2006^{1}$ & 32.9 & 21.2 & 270 & $<0.01$ \\
\hline 25 Jul 2006 & 30.2 & 21.2 & 110 & 0.11 \\
\hline
\end{tabular}

1 Days identified as having statistically significant excess mortality in table 3

\section{Regression}

\section{Deaths and temperature}

The relationship between daily mortality and mean, minimum and maximum daily temperatures was explored using regression analysis, but only the strongest relationships are reported here.

In summer the regression equation was:

Deaths $=1200.6(12.4)+6.6(0.6){ }^{*}$ temperature $^{1}$

This model indicates that for each $1^{\circ} \mathrm{C}$ increase in maximum CET above $21^{\circ} \mathrm{C}$, seven extra deaths occur (a 0.5 per cent increase based on the average number of daily deaths in summer). Although the model shows that temperature significantly predicts mortality, it only explains 8 per cent of the variance in summer mortality.

\footnotetext{
${ }^{1}$ The figures shown in brackets after the parameter estimates in the regression equations, for example 1200.6 (12.4), are the standard errors of the parameter estimates.
} 
The best regression model for predicting winter deaths was based on the mean Central England Temperature seven days earlier:

Deaths $=1802.9(11.9)-20.5(2.0){ }^{*}$ temperature $^{2}$

This model indicates that for each $1^{\circ} \mathrm{C}$ decrease in mean CET below $5^{\circ} \mathrm{C}, 21$ extra deaths occur seven days later (a 1.2 per cent increase based on the average number of daily deaths in winter). Although the model shows that temperature significantly predicts mortality, it only explains 7 per cent of the variance in winter mortality.

\section{Excess mortality and temperature}

The regression analysis was repeated using excess mortality regressed on temperature. For summer, excess mortality is zero when the maximum temperature is $20.7^{\circ} \mathrm{C}$.

In summer the regression equation was:

Excess mortality $=-203.0(13.6)+9.8(0.7) *$ Maximum Temperature ${ }^{1}$

This model shows that for each $1^{\circ} \mathrm{C}$ increase in maximum CET above $21^{\circ} \mathrm{C}, 10$ excess deaths occur. Although the model shows that temperature significantly predicts mortality, it only explains 20 per cent of the variance in excess summer mortality.

In winter the regression equation was:

Excess mortality $=-2.4(9.5)-6.5(2.3){ }^{*}$ Minimum Temperature $(\operatorname{lag} 4)^{1}$

For winter, the relationship between temperature and excess mortality was most significant at lag 4 (temperature four days earlier). This means that excess mortality is zero when the minimum temperature is $-0.4^{\circ} \mathrm{C}$. This model suggests that for each $1^{\circ} \mathrm{C}$ decrease in minimum CET below $0.4^{\circ} \mathrm{C}$, seven excess deaths occur. This amounts to a 0.4 per cent increase on average winter mortality. Although the model shows that temperature significantly predicts mortality, it only explains 1 per cent of the variance in excess winter mortality.

\section{Discussion}

\section{Heatwave mortality}

The analysis identified surprisingly few days with statistically significant excess mortality. Four out of the five excess mortality days coincided with very hot weather. During the August 2003 heatwave CETs peaked at $32.8^{\circ} \mathrm{C}$ on 9 August, and a large number of excess deaths were seen on the following two days. Temperatures on 9 August 2003 were classed as a heatwave since the maximum daily CET exceeded average values between 1971 and 2000 by more than $8^{\circ} \mathrm{C}$. The temperature on this day also reached the thresholds that were later put in place in the Heatwave Plan for England $\left(30^{\circ} \mathrm{C}\right.$ during the day and $15^{\circ} \mathrm{C}$ overnight). Similarly, in the July 2006 heatwave,

\footnotetext{
${ }^{2}$ The figures shown in brackets after the parameter estimates in the regression equations are the standard errors of the parameter estimates.
} 
CETs exceeded $30^{\circ} \mathrm{C}$ for two consecutive days on 18 and 19 July, and a peak in deaths was seen on 19 July. Both of these heatwaves have been reported in previous articles (Johnson et al., 2005 and Office for National Statistics, 2006). The short lag periods seen during these two heatwaves is consistent with other studies (Basu and Samet, 2002).

Unexpectedly, more than 300 excess deaths occurred on 19 June 2000. Investigation showed that 18 June was the hottest day of the year, with CETs reaching $29.4^{\circ} \mathrm{C}$, and temperatures remained hot on 19 June. The media reported that on 19 June, 58 illegal immigrants suffocated to death in the back of a lorry in Dover (BBC, 2000). Although this tragic event affected death registration statistics on this date, excess deaths were still statistically significant even when these deaths were excluded.

Of the summer heatwave days identified by this research (where daily maximum CET exceed the 10 -year average by $8^{\circ} \mathrm{C}$ ), only about half had unusually high mortality. Additionally, the two days with the highest mortality during the August 2003 heatwave were not the hottest days of that period and did not meet this heatwave threshold. This suggests that it is important to consider the days immediately following a heatwave, as excess mortality does not always occur on the hottest day. The first regression model found that a $1^{\circ} \mathrm{C}$ increase in temperature above $21^{\circ} \mathrm{C}$ was associated with an extra seven deaths, whilst the second model suggested an extra 10 deaths. However, the regression models only explained between 8 and 20 per cent of the variance in summer mortality, which may be because other factors, such as air pollution, are associated with summer mortality. For example, Rooney et al. (1998) found that up to 62 per cent of the excess mortality in England and Wales during the 1995 heatwave may have been attributable to concurrent increases in air pollution (ozone, nitrogen dioxide and particulates). More recent research from 90 US cities found a 0.21 per cent increase in mortality from non-external causes per $10-\mu \mathrm{g} / \mathrm{m} 3$ increase in PM10 at lag 1 (Dominici et al., 2003).

Health Protection agency (HPA) analysis of deaths in England during the summer of 2006 (when a heatwave occurred) showed that there were 75 extra deaths for each degree of temperature elevation (Health Protection Agency, 2006). This is higher than the 7 to 10 extra deaths estimated by the current research, suggesting that the model underestimates mortality. This difference is possibly due to the fact that the relationship between temperature and mortality is weaker in the 10 years of data we studied, compared with summer 2006 alone. A further explanation is that the relationship between mortality and temperature may not be linear at extremes of temperature, where mortality may increase more sharply. This is not captured by the linear regression performed in this analysis.

\section{Winter mortality}

The only winter day with statistically significant excess deaths was millennium eve (31 December 1999), which had the largest number of excess deaths of any day. This date was not exceptionally cold - the minimum CET was $3.4^{\circ} \mathrm{C}$, and CETs had not dropped below freezing on any day in the previous week. However, weekly GP consultation rates for influenza-like illness were high, and epidemic influenza activity (according to the current HPA threshold) was seen in the first and second week of January 2000 (Goddard et al., 2000). 
Analysis of cause of death showed that only 20 people died from influenza itself. However, influenza is rarely certified as the underlying cause of death, but can lead to life-threatening complications such as pneumonia (Curwen et al., 1990). The current research found that more people died from diseases of the respiratory system like bronchopneumonia, pneumonia and chronic airways obstruction on millennium eve, compared with the rest of the year. Furthermore, there was no increase in suicides on millennium eve (which might have been expected given the significance of the date). Therefore it is likely that the excess mortality seen on millennium eve is due to high levels of influenza circulating in the population.

Weekly consultation rates for influenza and influenza-like illness (Royal College of General Practitioners Weekly Returns) show that the largest influenza epidemic in recent times in England and Wales occurred in the winter of $1989 / 90$. High levels of influenza were also seen in the winters of 1993/94, 1996/97, 1998/99 and 1999/2000 (Goddard et al., 2000). These seasonal influenza epidemics coincide with years which had high levels of excess winter mortality, with the exception of 1993/94. In contrast, the winter of 1995/96 was particularly cold, and although excess winter mortality was higher than years with milder winters, it was not as high as years with influenza epidemics.

It is perhaps surprising that there were no other winter days with significant excess mortality. This may be because we are comparing daily mortality to the monthly average. Since mortality in the summer months is generally low and stable, and because the effects of heatwaves are more immediate, more of these excesses were identified in summer months. Mortality in the winter months was too variable to identify excess deaths using this method. The effect of cold on mortality is more gradual and has longer lasting effects than heatwaves (Analitis et al., 2008). So increases in deaths may be spread over a period of weeks, rather than days, meaning we are less likely to see individual days with exceptionally high mortality.

The method used in this research only identified five days with statistically significant excess mortality. Using the same method to look for days with statistically significant temperature extremes only identified one day. Moreover, the temperature on this day was only extreme relative to October and was not exceptionally cold in absolute terms. The known heatwaves of August 2003 and July 2006 were identified as unusual, but not significant temperature extremes. This suggests that these methods cannot be used to reliably identify extremes of temperature that are important to public health.

As expected, this research found a relationship between mortality and temperature three to seven days before in winter. The mortality data used in the current study is all cause mortality. The lag of three to seven days is slightly longer than found in other studies (The Eurowinter group, 1997). Additionally, the relationship was not as strong as expected. For example, Curwen and Devis (1988) found a correlation of -.76 between the number of excess winter deaths and the mean winter temperature, once the effects of winter influenza deaths had been controlled for. The regression analyses in the current study explained 7 per cent (first regression) and 1 per cent (second regression) of the variance in winter mortality. The difference between these two models is partly due to the fact that the first regression is predicting deaths, whereas the second model is predicting excess deaths, after some of the seasonal effects of mortality have been removed. In addition, because the second regression model required five years of data to predict excess 
mortality, only data from 1998 onwards was used. The first regression used data from the whole time period, 1993 onwards.

In contrast, Curwen and Devis (1988) modelled excess winter deaths between 1949 and 1985 and found a model including winter temperature, influenza deaths, and a time factor explained 88 per cent of the total annual variance in excess winter deaths. This again highlights the importance of influenza incidence to winter mortality.

The current study found that for each $1^{\circ} \mathrm{C}$ decrease in mean CET below $5^{\circ} \mathrm{C}, 21$ extra deaths occur (a 1.2 per cent increase based on the average number of daily deaths in winter), which is broadly similar to previous findings. The Eurowinter group (1997) found that mortality in London increased by 1.4 per cent for each $1^{\circ} \mathrm{C}$ decrease in mean temperature below $18^{\circ} \mathrm{C}$. Aylin et al. (2001) estimated that there was a 1.5 per cent higher odds of dying in winter for each $1^{\circ} \mathrm{C}$ decrease in mean temperature below the 10-year national average in Great Britain.

\section{Limitations and further research}

An important limitation of this research is that it focused only on temperature and did not take into account the impact of influenza on winter mortality. Further research would need to include influenza incidence data (for example from GP consultations) in the regression model. Future studies could also investigate including additional variables such as age, sex and cause of death. This may elucidate whether temperature has a more direct impact on mortality for certain subgroups (for example elderly people), or for certain causes of death (such as respiratory diseases). In addition, a more complex regression model could also take into account any nonlinear relationship between mortality and temperature that may exist.

One concern is that the relationship between mortality and temperature may be weaker with national level data (Central England Temperatures and England and Wales deaths), compared with local area data. This issue was illustrated during the August 2003 heatwave, when deaths in London increased by 42 per cent, compared with 17 per cent in England overall, possibly due to the nocturnal urban heat island in London (Johnson et al., 2005). Consequently, further studies will also need to examine the relationship between temperature and seasonal mortality at a local level.

This research has concentrated on temperature on a single day and how this relates to mortality on that day or on some day in the future (using lags). However, further research could examine whether hot or cold periods sustained over a period of days (or weeks) are more important for mortality than a single extremely hot or cold day. Additionally, it would be useful to investigate whether the rate of change in temperature is important.

When searching for days with statistically significant mortality, the Bonferroni procedure was used to correct for multiple tests. However, this could be seen as a conservative approach, as days with clinically important increases in deaths (for example, 20 per cent more deaths than expected) were not identified using this method. This was particularly the case in the winter months due to the variability of mortality in winter. 


\section{Conclusion}

This research has explored the relationship between temperature and mortality, in order to inform possible alternative methods of describing seasonal mortality. We identified five days with statistically significant excess mortality. Of these, four days occurred during very hot weather (three during known heatwaves) and one occurred in the winter during an influenza epidemic.

There was a weak significant relationship between temperature and mortality in both the summer and the winter, and temperature only explained a small proportion of the variance in mortality. This means that in winter, although mortality does tend to increase as it gets colder, this is not necessarily the case. Daily mortality in winter is very variable, and high levels of mortality can occur on relatively mild days. Similarly in summer, although several days of extremely high temperatures are usually associated with increased mortality, a single hot day does not always lead to excess deaths.

Consequently, we conclude that daily mortality cannot be predicted from temperature alone. Previous research suggests that this is because excess seasonal mortality is strongly influenced by the prevalence of influenza in winter, and to a lesser extent factors such as air pollution in summer.

\section{Acknowledgements}

The authors would like to thank the Met Office Hadley Centre who provided the Central England Temperature (HadCET) dataset. This dataset is available to download from the Hadley centre website: www.metoffice.gov.uk/hadobs. 


\section{References}

Analitis A, Katsouyanni K, Biggeri A, Baccini M, Forsberg B, Bisanti L, Kirchmayer U, Ballester F, Cadum E, Goodman P G, Hojs A, Sunyer J, Tiittanen P, and Michelozzi P (2008) 'Effects of Cold Weather on Mortality: Results From 15 European Cities Within the PHEWE Project' American Journal of Epidemiology 168,1397-1408.

Aylin P, Morris S, Wakefield J, Grossinho A, Jarup L, Elliot P (2001) 'Temperature, housing, deprivation and their relationship to excess winter mortality in Great Britain, 1986-1996.' International Journal of Epidemiology 30, 1100-1108.

Basu R and Samet J M (2002) 'Relation between elevated ambient temperature and mortality: a review of the epidemiologic evidence.' Epidemiologic Reviews, 24(2), 190-202.

BBC News online (2000) '58 dead in port lorry' available at: news.bbc.co.uk/1/hi/uk/796791.stm

Curwen M and Devis T (1988) 'Winter mortality, temperature and influenza: has the relationship changed in recent years?' Population Trends 54, 17-20.

Curwen, Dunnell and Ashley (1990) 'Hidden influenza deaths: 1989-90' Population Trends 61, 3133.

Department of Heath (2010) 'Heatwave plan for England: protecting health and reducing harm from extreme heat and heatwaves', available at:

www.dh.gov.uk/en/Publicationsandstatistics/Publications/PublicationsPolicyAndGuidance/DH 114 $\underline{430}$

Directgov (2010) - Information about winter fuel payments, available at: www.direct.gov.uk/en/Pensionsandretirementplanning/Benefits/Benefits/nRetirementDG 1001865 $\underline{7}$

Dominici F, McDermott A, Daniels M, Zeger S L, and Samet J M (2003) 'Mortality Among Residents of 90 Cities' published as part of the Health Effects Institute special report 'Revised Analyses of Time-Series Studies of Air Pollution and Health - Revised Analyses of the National Morbidity, Mortality, and Air Pollution Study, Part II - Revised Analyses of Selected Time-Series Studies

Donaldson G C and Keatinge W R (2003) 'Cold related mortality in England and Wales; influence of social class in working and retired age groups' Journal of Epidemiology and Community Health $57,790-791$.

The Eurowinter group (1997) 'Cold exposure and winter mortality from ischaemic heart disease, cerebrovascular disease, respiratory disease, and all causes in warm and cold regions of Europe' The Lancet 349, 1341-1346.

Field A (2009) 'Discovering statistics using SPSS', Sage Publications Ltd: London 
Goddard N L, Joseph C A, Zambon M, Nunn M, Fleming D, Watson J M (2000) 'Influenza surveillance in England and Wales: October 1999 to May 2000' Communicable Disease and Public Health 3 (4), 261-266.

Health Protection Agency (2006) 'Rapid evaluation of 2006 heatwave: Epidemiological aspects'. Available on the health protection agency website at: www.hpa.org.uk/Publications/EmergencyPreparationAndResponse/

Health Protection Agency (2010) Information about seasonal influenza, available at: www.hpa.org.uk/Topics/InfectiousDiseases/InfectionsAZ/Seasonallnfluenza/

Healy J D (2003) 'Excess winter mortality in Europe: a cross country analysis identifying key risk factors' Journal of Epidemiology and Community Health 57, 784-789.

Johnson H and Griffiths C (2003) 'Estimating excess winter mortality in England and Wales.' Health Statistics Quarterly 20, 19-24. Available on the Office for National Statistics website at: www.statistics.gov.uk/cci/article.asp?ID=1539\&Pos=4\&ColRank=1\&Rank=1

Johnson H, Kovats S R, McGregor G, Stedman J, Gibbs M, Walton H, Cook L, Black E (2005) 'The impact of the 2003 heatwave on mortality and hospital admissions in England' Health Statistics Quarterly 25, 6-11. Available on the Office for National Statistics website at: www.statistics.gov.uk/cci/article. asp? ID =1573\&Pos=3\&ColRank=1\&Rank=1

National Health Service (2010) Information about seasonal flu, available at: www.nhs.uk/Conditions/Flu-jab/Pages/Introduction.aspx

Office for National Statistics (2005) 'Summer Mortality: Deaths up in August heatwave' available at: www.statistics.gov.uk/CCl/nugget.asp?ID=480\&Pos=\&ColRank=1\&Rank=374

Office for National Statistics (2006) 'Report: Estimated daily mortality during July 2006 in England and Wales' Health Statistics Quarterly 32, 107-111. Available on the Office for National Statistics website at: $\underline{w w w . s t a t i s t i c s . g o v . u k / s t a t b a s e / P r o d u c t . a s p ? v l n k=15342}$

Office for National Statistics (2010) 'Statistical Bulletin: Excess winter mortality in England and Wales, 2009/10 (provisional) and 2008/09 (final)'. Available on the Office for National Statistics website at:

www.statistics.gov.uk/StatBase/Product.asp?vlnk=10805\&Pos=1\&ColRank=1\&Rank=272

Parker D E, Legg T P, and Folland C K (1992) 'A new daily Central England Temperature Series, 1772-1991'. International Journal of Climatology, 12, 317-342.

Rooney C, McMichael A J, Kovats R S and Coleman M P (1998) 'Excess mortality in England and Wales, and in Greater London, during the 1995 heatwave' Journal of Epidemiology and Community Health 52, 482-486. 
Wilkinson P, Landon M, Armstrong B, Stevenson S, Pattenden S, McKee M, and Fletcher T (2001) 'Cold comfort: The social and environmental determinants of excess winter deaths in England, 1986-96'. Published for the Joseph Rowntree Foundation by The Policy Press, Bristol. Available online at: www.jrf.org.uk/publications/cold-comfort-social-and-environmental-determinants-excesswinter-deaths-england-1986-19

World Health Organisation Regional Office for Europe (2010) - Information on excess winter deaths, available at: www.euro.who.int/ data/assets/pdf file/0008/97091/E89887.pdf 


\section{Annex A}

\section{Table A1 Example calculation of normalised daily deaths on 01 January 2000}

\begin{tabular}{lr}
\hline Statistic & Number \\
\hline Expected daily deaths in January $2000^{1}$ & 2,035 \\
Observed deaths on 1 January 2000 & 2,798 \\
Excess mortality on 1 January 2000 & 763 \\
Average daily excess mortality in January & -63.06 \\
Standard deviation of daily excess mortality in January & 291.98 \\
Normalised value for excess mortality on 1 January 2000 & 2.83 \\
Probability of normalised value & 0.005 \\
Five per cent critical value after Bonferroni correction & 3.80 \\
\hline
\end{tabular}

${ }^{1}$ Calculated using least squares regression on the last five years of data.

The probability of normalised excess mortality (EM) was calculated as $2(1-\Phi[E M])$, where $\Phi(Z)$ is the probability that a random selection from the Gaussian normal $(N(0,1))$ distribution is less than Z.

For example: The number of expected daily deaths in January 2000 (calculated using the least squares regression on the last five years of data) was 2,035 . The observed numbers of deaths on 01 January 2000 was 2,798 . Therefore the excess mortality on 01 January 2000 was 763 (2,798 $2,035)$. The mean and standard deviation of daily excess mortality in January (1998 to 2007) were -63.06 and 291.98 respectively. Therefore the normalised value for excess mortality on 01 January 2000 was 2.83: $(763--63.06) / 291.98=2.83$. So the probability of seeing excess mortality this extreme on 01 January 2000 was $0.005: 2(1-\Phi[2.83])=2(1-0.9977)=2 \times 0.0023=0.005$. This means that there was less than a 1 per cent chance of seeing excess mortality as extreme as this. However, the test statistic was adjusted using the Bonferroni method to correct for multiple significance tests (approximately 300 tests -30 days per month for 10 years of data). This means the probability would need to be less than $0.000167(2 \times(0.025 / 300))$ before it was statistically significant. So the 5 per cent critical value after Bonferroni correction was 3.80 , and because 2.83 is less than the critical value of 3.80 , the excess mortality was not statistically significant. So in the above example, although there was a small probability of seeing excess mortality of 763 in January, it was not statistically significant excess mortality. 


\section{Annex B}

\section{Example calculation of normalised daily temperatures on 19 June 2005}

The probability of each normalised temperature (NT) was calculated as:

$$
2(1-\Phi[\mathrm{NT}])
$$

For example: the mean CET on 19 June 2005 was $22.1^{\circ} \mathrm{C}$. The mean and standard deviation for June (1998 to 2007 ) were $14.7^{\circ} \mathrm{C}$ and $2.8^{\circ} \mathrm{C}$ respectively. Therefore the normalised temperature on 19 June 2005 was $(22.1-14.684) / 2.752=2.695$. So the probability of seeing a temperature this extreme on 19 June 2005 was: $2(1-\Phi[2.695])=2(1-0.9965)=2 \times 0.0035=0.007$. This means that there was less than a 1 per cent chance of seeing a temperature as extreme as this. However, the test statistic was adjusted using the Bonferroni method to correct for multiple significance tests (approximately 300 tests -30 days per month for 10 years of data). This means the probability would need to be less than $0.000167(2 \times(0.025 / 300))$ before it was statistically significant. So in the above example, although there was a small probability of seeing a mean temperature of $22.1^{\circ} \mathrm{C}$ in June, it was not a statistically significant extreme temperature. 